\title{
Development status and prospect of new energy technology
}

\author{
MingzhuZhang ${ }^{1,}$, XiaojingLi $^{1}$ \\ ${ }^{1}$ School of Mechanical Engineering, Tianjin University of Commerce, Tianjin, 300134, China
}

\begin{abstract}
In the current severe situation of continuous shortage of energy resources, the global energy structure is undergoing profound changes. New energy is the main direction of the energy transformation, and the iterative innovation of new energy technology is an important means to promote the transformation of the global energy industry. From the perspective of new energy technology, this paper mainly introduces wind power generation technology and photovoltaic power generation technology. Firstly, the basic principles of wind power and photovoltaic power generation technology are described; Secondly, it counts the current status of the global wind power and photovoltaic market in 2019 and the change trend of installed capacity during 2001-2019, further analyze the development status of these two new energy technologies; finally, it summarizes the development status of new energy technology and makes a prospect for its future development.
\end{abstract}

\section{Introduction}

When classifying energy according to the utilization technology, they can be divided into conventional energy and unconventional energy. Unconventional energy is also called new energy. New energy refers to the modern development and utilization of renewable energy using new technologies and new materials, focusing on the development and utilization of solar energy, wind energy, biomass energy, tidal energy, geothermal energy, hydrogen energy and nuclear energy. At present, these seven new energies have been developed and utilized to varying degrees, but solar energy, wind energy, biomass energy, and nuclear energy are the major ones. China has also participated in the "13th Five-Year" National Science and Technology Program in 2016. The "Plan" proposes to treat new energy as a new technology industry and focus on the development of the above four new energy industries. Among them, wind power and photovoltaic power generation are considered to be the most promising new energy technologies. In 2020, the China Development and Reform Commission and the Energy Administration jointly issued the "notice on publishing the 2020 wind power and photovoltaic power generation project on the grid", which is the turning point of China's wind power and photovoltaic development. At the same time, countries around the world are actively seeking the innovation of wind power and photoelectric technology, in order to further reduce the cost of the development and utilization of these two new energy sources. Therefore, this article emphatically introduces the wind power and solar power generation technologies, briefly describes their utilization principles, summarizes their development status in detail, and finally, based on the development status of the two. the status quo of new energy technology is summarized and prospected.

\section{Principle of new energy technology}

\subsection{Principle of wind power generation}

The realization of wind power generation technology depends on the wind turbine which is composed of windmill and generator. The principle of wind power generation is to use the wind to drive the wind turbine blade to rotate, and the blade drives the conductor to cut the magnetic induction line in the electromagnetic field of the motor to generate electric energy. The energy conversion of wind power generation can be described by Bezier wind energy theory, which has the following three assumptions: (1) there are infinite blades; (2) there is no hub; (3) when the air flows through the wind turbine, the air flow is uniform, the direction parallel to the axial direction of the wind turbine, no resistance. In an ideal state, the wind turbine wheel in the flowing atmosphere is shown in Figure 1:

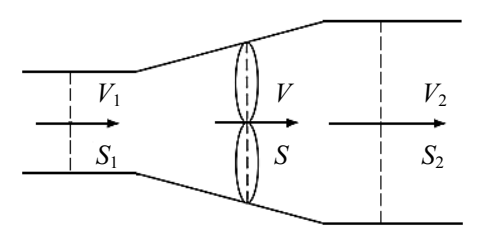

Figure 1. Wind turbine in flowing atmosphere in ideal condition.

According to the law of conservation of energy, Euler's theorem and continuity, the output power of the wind turbine under the assumption of Betz theory is:

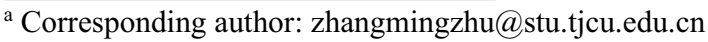




$$
P=\frac{1}{4} \rho S\left(V_{1}^{2}-V_{2}^{2}\right)\left(V_{1}-V_{2}\right)
$$

Where: $V_{1}$-wind speed upstream of wind turbine; $V$ - the actual wind speed passing through the wind turbine; $V_{2}$-wind speed downstream of wind turbine; $S_{1}$ - upstream section of wind turbine; $S$-section swept by wind turbine; $S_{2}$-downstream section of wind turbine; $\rho$-air density.

\subsection{Principle of photovoltaic power generation}

The realization of photovoltaic power generation technology depends on the solar photovoltaic module which can directly convert light energy into electric energy. Its power generation principle is the "photovoltaic" effect of the semiconductor interface. It can be described with a single diode model, as shown in Figure 2. In this diode model, the output power of the photovoltaic cell can be expressed as:

$$
P_{L}=I_{L} V-I_{d} V\left[\exp \left(\frac{q V_{\mathrm{d}}}{M K T}\right)-1\right]
$$

Where: $I_{\mathrm{L}}$-photocurrent; $V$-PV cell output voltage; $I_{\mathrm{d}}$ - equivalent diode current; $q$-electronic charge; $V_{\mathrm{d}}-$ equivalent diode terminal voltage; $M$-diode quality factor; $K$-Boltzmann constant; $T$-thermodynamic temperature.

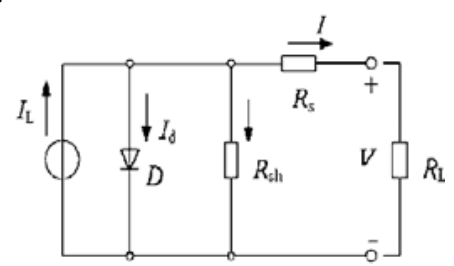

Figure 2. Photovoltaic cell equivalent circuit diagram.

\section{Principle of new energy technology}

\subsection{Status of wind power technology}

According to statistics from the Global Wind Energy Council (GWEC), the global wind power market has developed considerably in 2019, with new installed capacity of $60.3 \mathrm{GW}$, an increase of $19 \%$ compared to 2018. Among them, the new installed capacity of onshore wind power is $54.2 \mathrm{GW}$, and that of offshore wind power is $6.1 \mathrm{GW}$. The proportion of each country can be seen from figures 3(a) and 3(b); The cumulative installed capacity exceeded $650 \mathrm{GW}$, an increase of $10 \%$ compared to 2018. Among them, the cumulative installed capacity of onshore wind power was $621 \mathrm{GW}$, and the cumulative installed capacity of offshore wind power was 29.1 GW, as shown in Figures 4(a) and 4(b) [1]. Statistics on the new and cumulative installed capacity of global wind power from 2001 to 2019 are shown in Figures 5 and 6 . It can be seen that it is increasing year by year. This is mainly due to the continuous innovation and progress of wind power technology, which has reduced the cost of wind power and further expanded the market ${ }^{[2]}$.

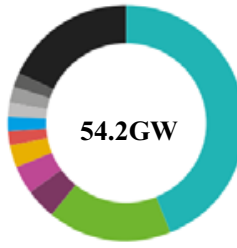

(a) onshore

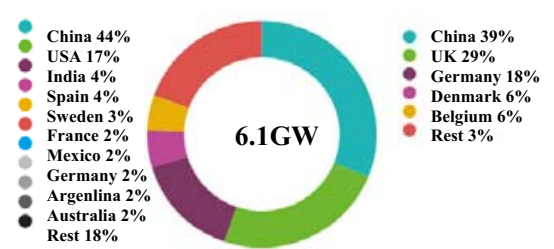

(b)offshore
Figure 3. Proportion of wind power new installed capacity in countries in $2019(\%)$.

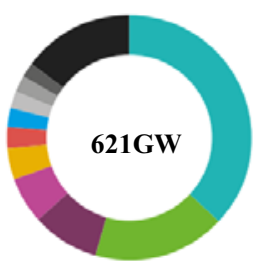

(a) onshore

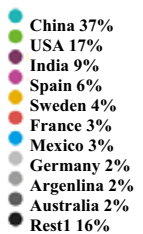

Rest1 16\% (b)offshore

Figure 4. Proportion of wind power cumulative installed capacity in countries in 2019(\%).

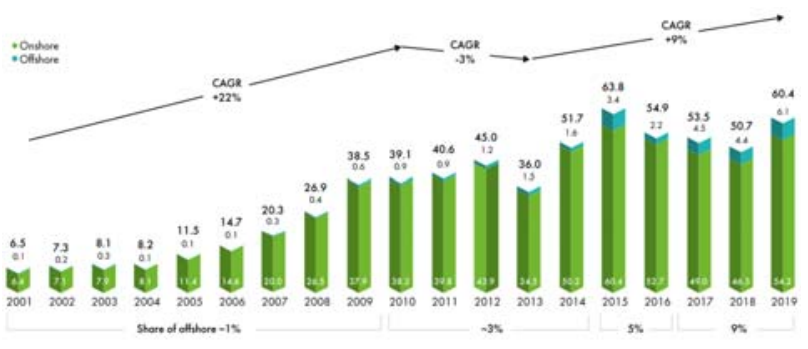

Figure 5. 2001-2019 global wind power new installed capacity trend $(\mathrm{GW})$.

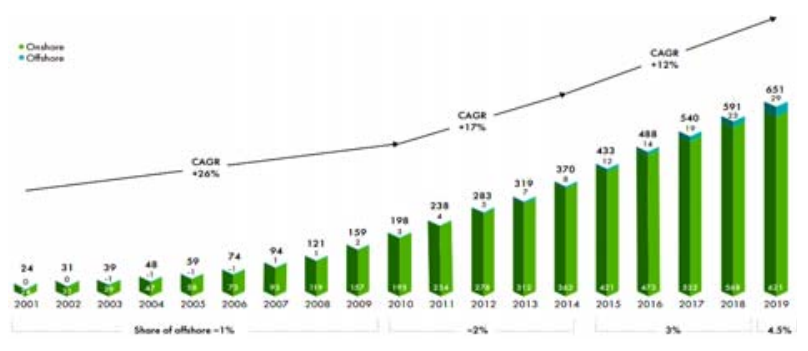

Figure 6. 2001-2019 global wind power cumulative installed capacity trend $(\mathrm{GW})$.

At present, wind power generation technologies mainly include three types: onshore, offshore, and highaltitude. Onshore wind power technology is relatively mature in the world. Most countries onshore smallcapacity wind turbines have reached the level of commercialization. The development of offshore wind power technology in abroad has entered the research and design stage of large-scale offshore wind turbine. Domestic is still a big gap between the research and engineering design coordination of offshore wind turbines and the international technology level. Highaltitude wind power technology is in the preliminary stage of exploration worldwide, and no dedicated wind turbines have yet come out. The current research hotspots of wind power technology mainly focus on the integration and transformation of cross-industry and 
cross-energy technologies. In this regard, foreign research is more active than domestic, and it is in a leading position in terms of basic theory, basic technology and material application.

In terms of onshore wind power technology, Tao Xu ${ }^{[3]}$ summarized the development history of wind turbines and found that, the overall design, manufacturing, testing and reliability of onshore wind turbines in foreign countries are very high, and the small capacity of 1.5$6 \mathrm{MW}$ has been running in batches, but there is a big gap between China's overall test level and the international mature technology; Guodong $\mathrm{Xu}$ et al. ${ }^{[4]}$ through the research on the current situation of wind power technology believe that, abroad onshore wind power technology is quite mature. $4-7 \mathrm{MW}$ wind turbines have been industrialized, $8-10 \mathrm{MW}$ wind turbine prototypes have been on-hook, and the overall design has entered the 10MW design stage. China's onshore wind power technology is gradually mature, $1.5-4 \mathrm{MW}$ wind turbines have sufficient supply capacity, and some 5-6MW wind turbines have been offline. In terms of offshore wind power technology, Hesheng Qi et al. ${ }^{[5]}$ through studying the wind power development policies of various countries found that, the research hotspot of offshore wind power technology in abroad is the design and research of large-scale offshore wind turbines. Domestic offshore wind power technology is focusing on the key technologies of offshore wind turbine manufacturing and offshore infrastructure; Wei Cui et al. ${ }^{[6]}$ also conducted related research and found that abroad are very good at cross-industry technology integration and technology transformation, and are in a leading position in offshore wind power intelligent monitoring, intelligent operation and maintenance. China's offshore wind industrial chain continues to progress, engineering construction and after-sales maintenance and other aspects have made certain progress, China has entered the period of largescale development.

In addition, to greatly increase the share of wind energy in the energy market and accelerate the transformation of the global energy structure, it is necessary to carry out a series of changes in the past wind energy technology, and replace single renewable energy with energy integration technology through cross-industry cooperation. combination of wind energy and other energy/energy storage technologies is a key issue in the renewable energy industry. Hydrogen production from offshore wind power is a key technology for cross-industry integration that is widely explored. It includes two solutions, as shown in Figures 7 and 8 .

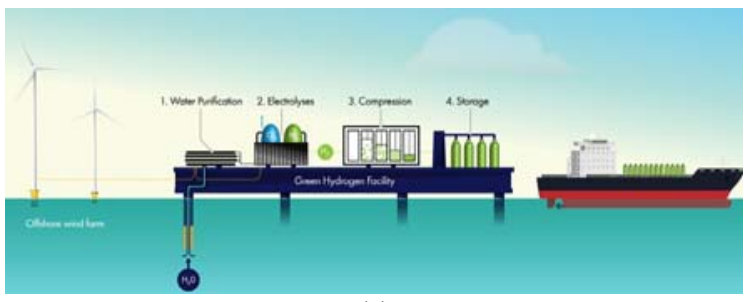

(a)

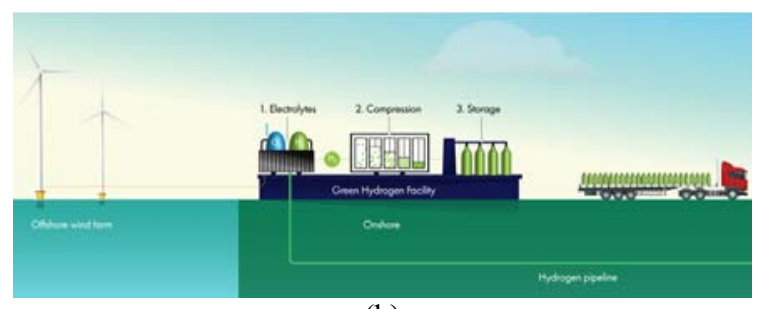

(b)

Figure 7. Offshore wind energy hydrogen production solution

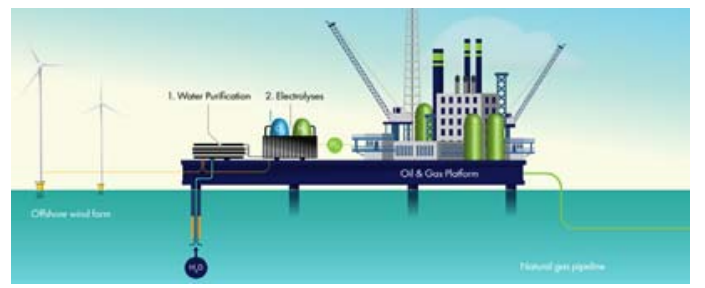

Figure 8. Offshore wind energy hydrogen production solution

\subsection{Status of photovoltaic power technology}

According to statistics from the International Energy Agency (IEA), the global photovoltaic market has developed well in 2019, with new installed capacity of $115 \mathrm{GW}$, the proportion of countries is shown in Figure 9; The cumulative installed capacity reached $627 \mathrm{GW}$, Figure 10 shows the proportion of each country [7]. Statistics on the new and cumulative installed capacity of global photovoltaic from 2001 to 2019 , the results are shown in Figures 11 and 12. It can be seen that the photovoltaic installed capacity has continued to rise steadily in the past two decades. This is mainly due to the innovation of photovoltaic technology, which promotes the transformation and upgrading of the photovoltaic industry, and makes the development prospects of the photovoltaic market broader.

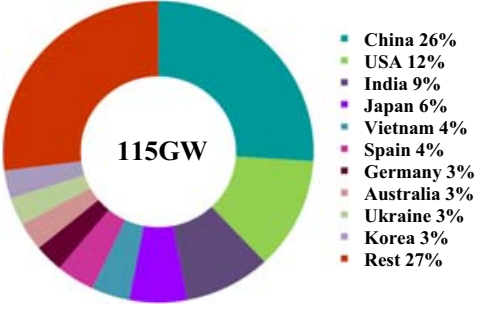

Figure 9. Proportion of photovoltaic power new installed capacity in countries in 2019(\%).

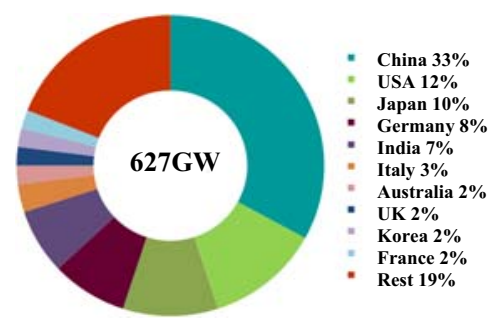

Figure 10. Proportion of photovoltaic power new installed capacity in countries in 2019(\%). 


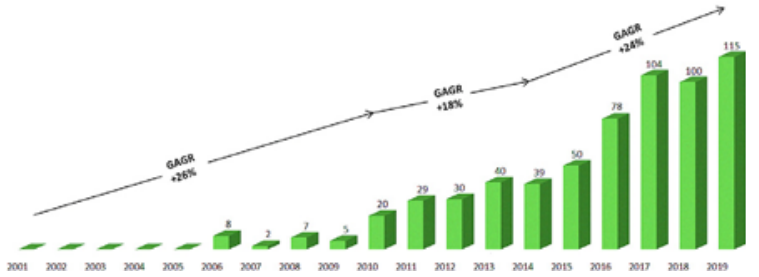

Figure 11. 2001-2019 global photovoltaic new installed capacity trend $(\mathrm{GW})$.

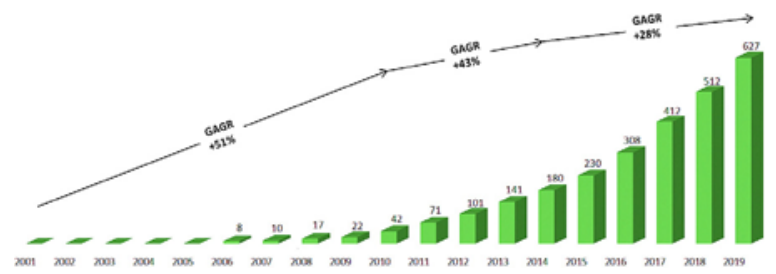

Figure 12. 2001-2019 global photovoltaic cumulative installed capacity trend $(\mathrm{GW})$.

As far as the current photovoltaic power generation technology is concerned, the commonly used glass crystalline silicon solar cell technology is quite mature, and the focus on further improving its efficiency can only be the breakthrough of new materials and new coatings. In addition, the research hotspots of photovoltaic power generation technology also include thin film battery technology, floating photovoltaic technology, double-sided photovoltaic technology and cross-industry technology integration.

In the development of photovoltaic power generation technology, Europe is still at the forefront of the world. The German organic thin-film solar cell manufacturer Heliatek uses OPV multi-junction cell technology to create a new record of $13.2 \%$ conversion efficiency, which also provides further verification for heliatek's unique technology of small molecule vacuum evaporation on plastic film ${ }^{[8]}$; The current development of solar cells tends to be thinner and flexible. Wang Hui ${ }^{[9]}$ et al. conducted a study on the efficiency of thin film cells, and the results showed that the highest efficiency of flexible silicon thin film solar cells was $16.3 \%$, the highest efficiency of flexible cadmium telluride solar cells was $13.8 \%$, and the highest efficiency of flexible copper indium gallium selenium solar cells was $20.4 \%$; The emergence of floating photovoltaic technology is a turning point in the photovoltaic power generation market. It not only solves the problem of land occupation for photovoltaic system construction, but also brings a series of symbiotic benefits, which has higher power generation efficiency than terrestrial photovoltaic systems. Nearly 300 floating photovoltaic technology projects have been recorded worldwide, of which the world's largest floating photovoltaic station was installed in Anhui, China ${ }^{[10]}$; Compared with the traditional photovoltaic power generation technology, the doublesided photovoltaic technology can capture more light and improve the power generation to a certain extent. According to the different ground reflection conditions, the power generation can be increased by $5 \%-27 \%{ }^{[11]}$.

The advancement of photovoltaic technology has brought more opportunities to photovoltaic power generation. The integration of multiple energy technologies such as wind-solar diesel combined power generation, photovoltaic-biomass combined power generation et al. make photovoltaic power generation more widely used. It is worth noting that the technical integration of floating photovoltaic power stations and hydropower stations is one of the current research hotspots. The first hybrid floating solar hydropower station is built in Portugal is shown in Figure $13^{[12]}$.

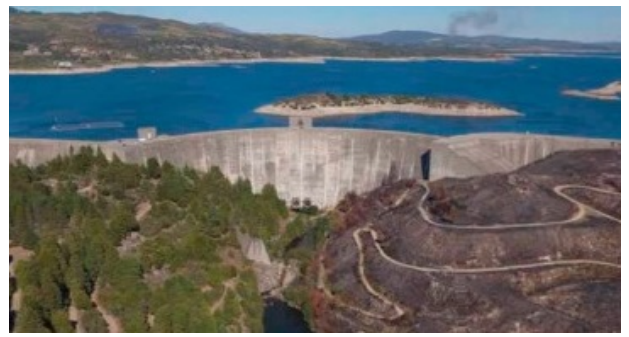

Figure 13. The first hybrid floating solar hydroelectric power station installed in Montaleger, Portugal

\section{Conclusions and prospects of the status quo of new energy technologies}

Facing the demand for low-carbon and clean energy in the future, the use of new energy technologies to develop and utilize new energy is an important way to achieve zero carbon emissions. Therefore, this paper summarizes and prospects the current situation of new energy technology based on the current situation of wind power and photoelectric technologies:

(1) The trend chart of installed capacity of wind power and photovoltaic power in the past 20 years shows from the side that new energy technologies are in a period of rapid innovation. In order to make breakthroughs in various new energy technologies, it is necessary to solidify the research of basic materials, advanced manufacturing and information communication and other basic disciplines, and realize the development of original technological innovation.

(2) It can be seen from the aspects of wind power and photovoltaic intelligence that the current new energy technology is at the stage of cross-connection and innovation between energy and non-energy-related technologies. In the future, new energy technologies will tend to be cross-linked and joint in multiple fields, and more emphasis should be placed on basic theoretical research in cross-directions such as energy, materials, environment, information and data.

(3) It can be seen from the case of the combination of different energy types that the current new energy technology has made certain progress in the mutual penetration and integration of different types of energy. Therefore, on the basis of the common progress of various new energy technologies, the construction of a new generation of safe, low-carbon, clean and efficient integrated energy system is the future technological development trend. 


\section{References}

1. GWC. Global Wind Report 2019[R].2020.

2. YilinSun.J.WE, 46-51 (2020).

3. TaoXu.C.WEI, 36-37(2016).

4. GuoDongXu,HangyeYe.J.CAE,44-50(2018).

5. HeshengQi,ShujuHu.J.CAS, 173-181(2016)

6. WeiCui,Ascle.J.EAEE,1-5(2019)

7. IEA.Snapshot of Global PV Markets 2020[R].2020.

8. REPC. China Photovoltaic Development Report 2016[R].2016.

9. HuiWang,YuexianCao.J.CAE,66-73(2018)

10. S. Gorjian, H. Sharon,H. Ebadi.J.JCP,278(2020)

11. CRE.J.SE.5-15(2020)

12. IRENA. Global Renewables Outlook[R].2020. 